LA-UR-98-

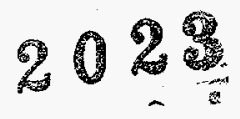

December 24, 1997

\title{
Title: Nuclear Fuels Technologies Thermally Induced Gallium Removal System (TIGRS) Fiscal Year 1998 Research and Development Test Plan
}

Author:

Submitted to:

John J. Buksa

Darryl P. Butt

Kennneth Chidester

Scott F. DeMuth

George J. Havrilla

Christopher A. James

David G. Kolman

General Distribution

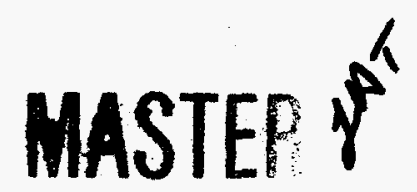

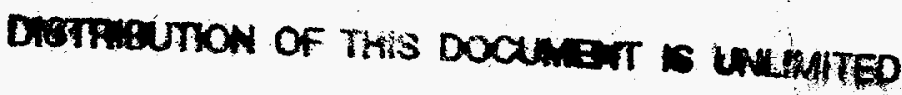

\section{Los Alamos}

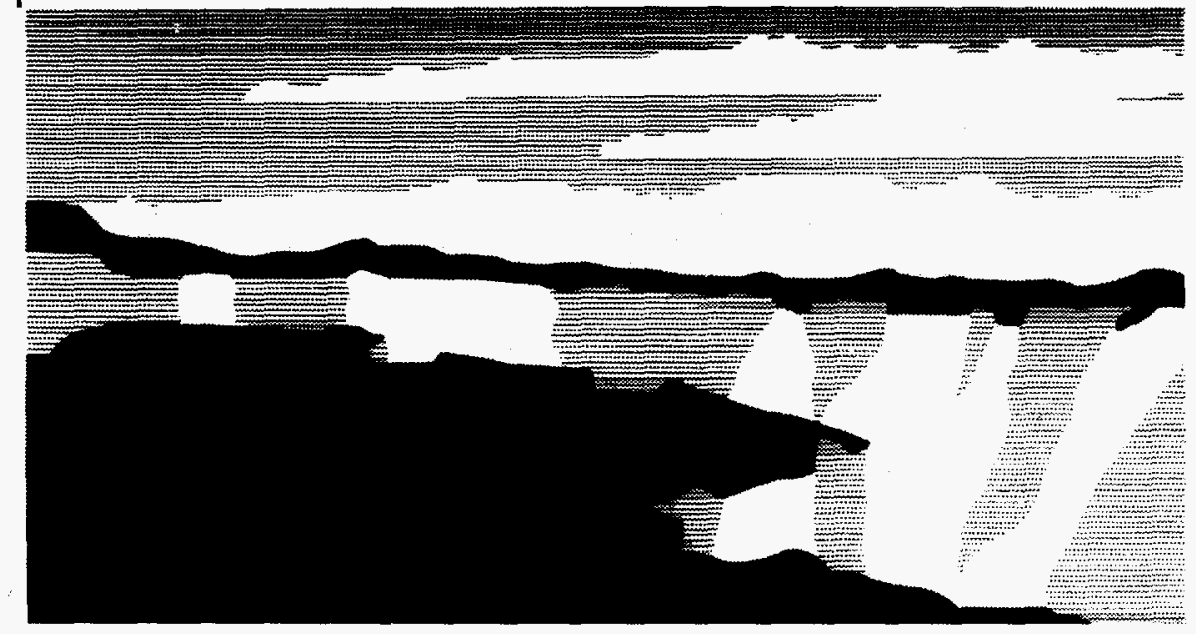

NATIONAL LABORATORY

Los Alamos National Laboratory, an affirmative action/equal opportunity employer, is operated by the University of California for the U.S Department of Energy under contract W-7405-ENG-36. By acceptance of this article, the publisher recognizes that the U.S. Government retains a nonexclusive, royalty-free license to publish or reproduce the published form of this contribution, or to allow others to do so, for $U . S$. Government purposes. The Los Alamos National Laboratory requests that the publisher identify this article as work performed under the auspices of the U.S. Department of Energy. Los Alamos National Laboratory strongly supports academic freedom and a researcher's right to publish; therefore, the Laboratory as an institution does not endorse the viewpoint of a publication or guarantee its technical correctness. 


\section{DISCLAIMER}

This report was prepared as an account of work sponsored by an agency of the United States Government. Neither the United States Government nor any agency thereof, nor any of their employees, makes any warranty, express or implied, or assumes any legal liability or responsibility for the accuracy, completeness, or usefulness of any information, apparatus, product, or process disclosed, or represents that its use would not infringe privately owned rights. Reference herein to any specific commercial product, process, or service by trade name, trademark, manufacturer, or otherwise does not necessarily constitute or imply its endorsement, recommendation, or favoring by the United States Government or any agency thereof. The views and opinions of authors expressed herein do not necessarily state or reflect those of the United States Government or any agency thereof. 


\section{DISCLAIMER}

Portions of this document may be illegible in electronic image products. Images are produced from the best available original document. 


\section{Nuclear Fuels Technologies}

Thermally Induced Gallium Removal System (TIGRS)

Fiscal Year 1998 Research and Development Test Plan

Los Alamos National Laboratory

John J. Buksa

Darryl P. Butt

Kennneth Chidester

Scott F. DeMuth

George J. Havrilla

Christopher A. James

David G. Kolman

December 24, 1997 


\section{TABLE OF CONTENTS}

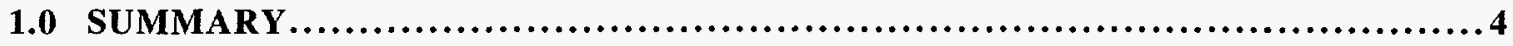

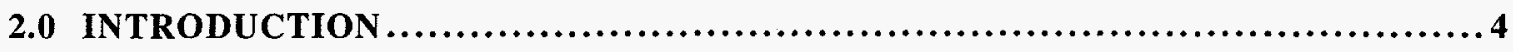

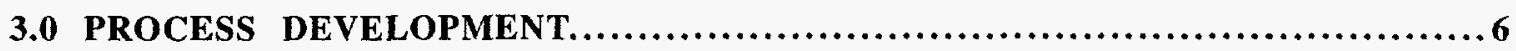

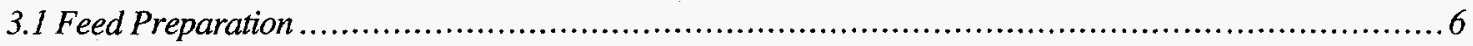

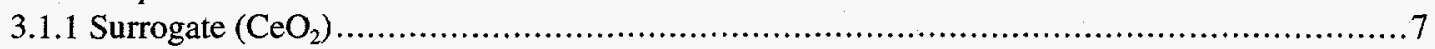

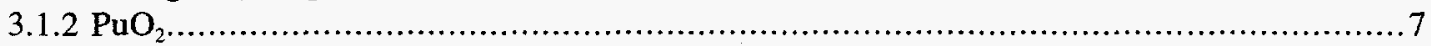

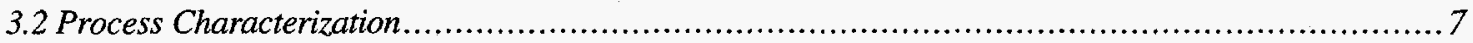

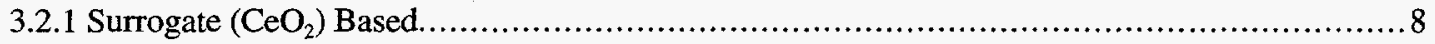

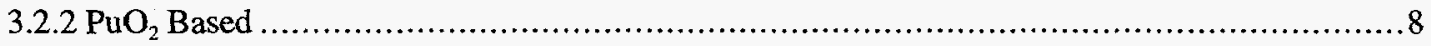

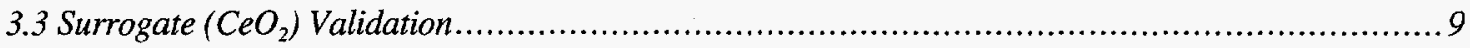

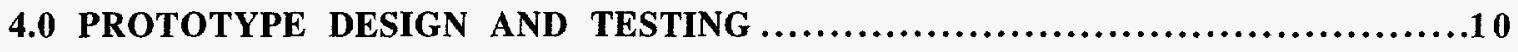

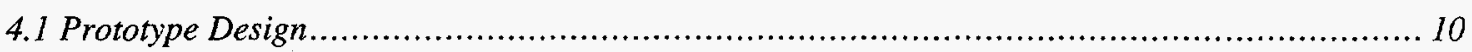

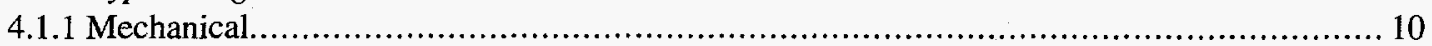

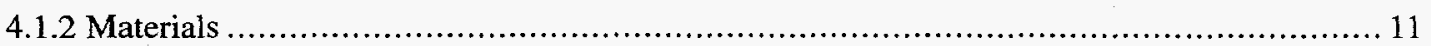

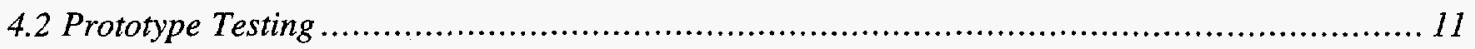

5.0 MAJOR MILESTONES/DELIVERABLES..................................1 1 


\subsection{SUMMARY}

As TIGRS has evolved from the conceptual to application phase, the requirements have become more clearly defined, and consequently, so must the test planning. While this Test Plan is concerned with only the details of FY98, the entire test program (which is to be completed in FY99) is outlined here to aid in the understanding of the FY98 activities. It is important to note that a significant amount of TIGRS related R\&D work has already occurred.

This R\&D test program has been essentially divided into two major activities. These two activities form the basis of this Test Plan, and can be described as (1) process development which leads to the prototypic design, and (2) prototypic design and testing. Both of these major activities will be accomplished through testing with the use of cold surrogate $\left(\mathrm{CeO}_{2}\right)$ and hot $\left(\mathrm{PuO}_{2}\right)$ feed materials. Following feed fabrication development and validation, the surrogate feed material will be used to verify material compatibility and process material handling for the prototypic equipment. The $\mathrm{PuO}_{2}$ feed material will be used to demonstrate adequate gallium separation and to optimize process operating conditions.

\subsection{INTRODUCTION}

This document details the research and development (R\&D) activities that will be conducted in Fiscal Year 1998 (FY98) by the Thermally Induced Gallium Removal System (TIGRS) team for the Department of Energy Office of Fissile Materials Disposition. This work is a continuation and extension of experimental activities that have been conducted in support of using weapons-derived plutonium in the fabrication of mixed-oxide (MOX) nuclear fuel for reactor-based plutonium disposition. The ultimate purpose of this work is to demonstrate adequate Thermally Induced Gallium Removal with a prototypic system. This Test Plan presents more than the FY98 R\&D efforts in order to frame the Task in its entirety. It is felt that to understand the motives behind each individual effort in this Test Plan, the reader must be familiar with the entire Task effort. This entire Task is essentially a two year effort culminating in the final prototypic demonstration of the TIGR process. The specifics of the FY99 effort are not discussed in this document; however, top-level objectives for both FY98 and FY99 will be explained and included in the Schedule Section.

To achieve the TIGRS Program objectives, R\&D activities during the next two years will be focused on (1) process development leading to a prototypic TIGRS design, and (2) prototypic TIGRS design and testing leading to and including a prototypic demonstration of TIGRS operation. Both the process development and system testing efforts will consist of a series of surrogate-based cold tests and plutonium-based hot tests. Some of this testing has already occurred and will continue into FY99.

Surrogate-Based Cold Tests. These tests are oriented toward answering early questions regarding (1) the solid-based phase structure of gallium in $\mathrm{PuO}_{2}$-like systems, (2) the gallium evolution mechanisms in $\mathrm{PuO}_{2}$-like systems, and (3) the functionality and reliability of the prototype TIGRS hardware.

Process Development. Knowledge of the solid-based phase structure can be used to infer the maximum gallium which can be separated from plutonium. This information has produced early evidence that the TIGR process has a reasonable chance of success. Additionally, it may aid in the validation of the surrogate, which will be important for cold prototypic testing. The data obtained from cold testing allows an early review of the TIGR process applicability. 
Process Development. Determination of the predominant gallium separation mechanisms (i.e. diffusion within the particle, chemical kinetics, or mass transfer between the solid and gas phases) can aid in the selection of a prototypic TIGR design. For instance, early data indicate the hydrogen gas velocity and consequent mass transfer rate between the solid and gas phases may significantly affect the rate of gallium separation. From this one can infer that the TIGRS design should have the capability to adjust the gas/particle mixing. An example of how this can be achieved is an inclined-rotating versus batch-type calciner. Further testing is needed to confirm these early data. This type of data obtained from cold testing will allow an early review of potential off-the-shelf applicable TIGR processing equipment.

Prototypic Design and Testing. Use of a cold surrogate for establishing the functionality and reliability of the prototypic TIGRS is necessary for a number of reasons.

First, typical devices used for similar processing of $\mathrm{PuO}_{2}$ such as calciners, are generally operated at temperatures significantly less than may be required for gallium separation. Consequently, while an off-the-shelf design such as that of a calciner may be selected, the materials may be different due to a higher operating temperature. The use of new materials even with an established design creates the need for some degree of mechanical and reliability testing. If hot (plutonium) feed rather than cold (surrogate) feed were used for this testing, it would be much more difficult (if even possible) to correct mechanical problems.

Second, gallium compatibility with the TIGRS materials must be established for reliability reasons. This effort will require significantly less effort and cost with a cold feed than a hot feed, with little or no compromise in the data applicability.

Third, it may be necessary to use a gallium getter, coupled with occasional bakeout of the TIGRS, to minimize degradation of system components. The efficiency of such a device can be more easily, and less expensively, demonstrated with a cold feed than with a hot feed.

And finally, the material handling itself can more easily and less expensively be demonstrated with a cold feed rather than a hot feed. In particular, should a device similar to an inclined-rotating calciner be used, the particle movement will likely need to be demonstrated due to the potentially higher operating temperature.

Plutonium-Based Hot Tests. These tests will be oriented toward (1) determining the controlling gallium evolution mechanisms in $\mathrm{PuO}_{2}$, (2) selecting an appropriate TIGRS design for industrial application, (3) determining the optimum processing conditions, and (4) demonstrating prototypic TIGRS processing and equipment reliability.

Process Development. Determination of the controlling gallium separation mechanisms (i.e. diffusion within the particle, chemical kinetics, or mass transfer between solid and gas phases) will dictate the prototypic TIGR design. The data from hot (plutonium) testing will be used to validate the results obtained from the surrogate testing and to refine the conclusions derived from the surrogate data. For 
instance, data from hot testing will be used to establish the prototypic operating temperature range which will lead to selection of materials for the prototypic design.

Prototypic Design and Testing. Preparation of the prototypic design will require evaluating the process development data to select the complete range of processing conditions, such as hydrogen gas velocity, temperature, processing time, and feed rate. Following fabrication or purchase of the prototypic processing unit, it will be necessary to evaluate its performance and reliability. While the cold testing will be used to evaluate mechanical reliability, material compatibility, and gallium getter efficiency, the prototypic hot testing will be used to demonstrate the process adequacy and to optimize the processing conditions.

\subsection{PROCESS DEVELOPMENT}

The Process Development task will be focused upon the following efforts to demonstrate the TIGR process adequacy and to aid in the selection of prototypic processing equipment and processing conditions.

- Producing an adequate supply of well characterized prototypic surrogate $\left(\mathrm{CeO}_{2}\right)$ and $\mathrm{PuO}_{2}$ feed material.

- Surrogate testing to determine the phase structure of cerium-gallium oxide and the rate limiting mechanisms of gallium evolution from cerium.

The phase structure will be determined by a variety of analytical methods including scanning electron microscope (SEM) and X-ray fluorescence (XRF) for the gallium distribution.

The gallium evolution mechanisms to be studied are:

(1) Diffusion within the particle $\left(\mathrm{Ga}_{2} \mathrm{O}_{3}, \mathrm{Ga}_{2} \mathrm{O}\right.$, and $\left.\mathrm{H}_{2}\right)$.

(2) Chemical kinetics $\left(\mathrm{Ga}_{2} \mathrm{O}_{3}\right.$ reduction to $\left.\mathrm{Ga}_{2} \mathrm{O}\right)$.

(3) Solid/gas mass transfer (hydrogen adsorption on the particle surface and $\mathrm{Ga}_{2} \mathrm{O}$ sublimation or vaporization from the particle surface to the gas). It is not yet known whether the $\mathrm{Ga}_{2} \mathrm{O}$ exists as a solid or liquid on the particle surface; hence, it may sublime or vaporize.

- $\mathrm{PuO}_{2}$ testing to validate the surrogate applicability.

- $\mathrm{PuO}_{2}$ testing to begin the determination of prototypic processing conditions.

\subsection{Feed Preparation}

To conduct the process development and prototypic testing, adequate supplies of both surrogate-based and plutonium-based feed material must be fabricated. It is essential that this material, for both surrogate-based and plutonium-based feedstock, be as representative of prototypic material as possible. For this reason, multiple fabrication processes will be evaluated. 


\subsubsection{Surrogate $\left(\mathrm{CeO}_{2}\right)$}

The following potential methods for producing the $\mathrm{CeO}_{2}$ will be evaluated to produce a surrogate with the proper phase structure and particle morphology.

Pressing/Sintering/Milling

This involves pressing followed by sintering and milling of $\mathrm{CeO}_{2}$ to achieve

Precipitation proper particle morphology.

Dissolution in acid followed by precipitation such as the oxalate process used for plutonium. The precipitate can then be oxidized by a calcination process.

Hydride/Oxide

This is essentially the LLNL 2-Step process developed for plutonium.

\subsection{2 $\mathrm{PuO}_{2}$}

There are potentially three sources of prototypic weapons-based $\mathrm{PuO}_{2}$ which contains gallium. This feed material in general must be characterized with regard to gallium concentration and particle morphology.

$\mathrm{PuO}_{2}$ from the LLNL 3-Step process. As of 22 December 1997, LANL has approximately $350 \mathrm{~g}$ of this material remaining. All $\sim 350 \mathrm{~g}$ have been characterized for gallium concentration and particle morphology (particle size and surface area).

$\mathrm{PuO}_{2}$ from the LLNL 2-Step process. As of 22 December 1997, LANL has approximately $1500 \mathrm{~g}$ of this material. All $\sim 1500 \mathrm{~g}$ have been characterized for gallium concentration, but the particle morphology has not been determined.

$\mathrm{PuO}_{2}$ directly oxidized from metal ingots. Currently LANL does not have any of this material; however, production can begin in early 1998 if necessary.

Characterization would be required.

\subsection{Process Characterization}

An important objective of the Process Development effort is the selection of prototypic processing conditions. These process conditions will dictate the type of processing equipment required and the materials.

If it is determined that the hydrogen gas velocity has a significant impact on the gallium separation rate, and that by manipulating processing temperature and processing time alone adequate gallium separation can not be achieved, a device which can significantly adjust the gas/particle interaction such as an inclined rotating kiln may be required.

If it is determined that the hydrogen gas velocity does not significantly affect the gallium separation rate, or that manipulation of processing temperature and processing time alone can achieve adequate gallium separation, then batch-type processing with a fixed bed may be satisfactory. Equipment required for batch-type fixed bed processing is of a simpler design and operation than a device like an inclined rotating kiln. For such a case, the prototypic processing unit would be less expensive to fabricate and operate. 


\subsubsection{Surrogate $\left(\mathrm{CeO}_{2}\right)$ Based}

The plutonium-gallium oxide phase structure will dictate the maximum amount of gallium which can be separated by the TIGR process. While a single $\mathrm{Ga}_{2} \mathrm{O}_{3}$ phase should be easily reduced with hydrogen to the volatile $\mathrm{Ga}_{2} \mathrm{O}$ species, a more complex phase with both plutonium and gallium in solution might not be amenable to $\mathrm{Ga}_{2} \mathrm{O}$ formation. Currently, a method for characterizing the phase structure of plutonium-gallium compounds at gallium concentrations less than $10 \mathrm{wt} \%$ has not been found. Consequently, determining the phase structure for prototypic weapons-based material is not yet possible. However, it is possible to determine the $\mathrm{CeO}_{2}$ surrogate phase structure with prototypic gallium concentrations of less than $1 \mathrm{wt} \%$. In light of this information, surrogate phase structure studies have been initiated to ascertain the thermodynamic similarities between ceriumgallium oxide and plutonium-gallium oxide, at gallium concentrations amenable to phase structure analysis for both the surrogate and plutonium systems. Following validation of the cerium and plutonium phase structure similarities, conclusions drawn from surrogate phase structure analysis at prototypic gallium concentrations will be extrapolated to the plutonium phase structure. This may provide data regarding the theoretical maximum gallium separation from plutonium by the TIGR process.

\subsection{2 $\mathrm{PuO}_{2}$ Based}

Prototypic $\mathrm{PuO}_{2}$ will be used to establish the processing conditions which are required for the system design. The process parameters which will be studied are summarized in the following, and the detailed test matrices are shown as Tables 3.2.2-1 and 3.2.2-2.

Time

Time can affect the degree of sintering as well as the degree of gallium separation; therefore, it is desirable to maximize processing time to increase gallium separation, but to minimize process time in order to limit adverse sintering effects.

\section{Temperature}

Temperature affects the TIGR process in a fashion similar to time.

Gas velocity of the reducing agent $\left(\mathrm{H}_{2}\right)$

The hydrogen gas velocity will alter the mass transfer coefficients for transfer of hydrogen from the gas phase to the particle, and for transfer of $\mathrm{Ga}_{2} \mathrm{O}$ from the particle to the gas phase. Increasing gas velocity may increase the rate of gallium separation; however, increasing gas velocity can also make plutonium powder management more difficult.

Partial pressure of reducing agent $\left(\mathrm{H}_{2}\right)$

Adjusting the partial pressure (i.e. concentration) of the reducing agent hydrogen, while maintaining the overall gas pressure and velocity constant, can provide evidence as to whether the chemical kinetics affect the gallium separation rate. However, there is little reason to use less than the maximum of $6 \% \mathrm{H}_{2}$ allowed by safety considerations. Therefore, this process parameter will probably not be evaluated. 
Sample size

Sample size can affect the hydrodynamics of the gas/particle interaction. Since hydrogen must enter the particle, and $\mathrm{Ga}_{2} \mathrm{O}$ must leave the particle, the batch size for a fixed particle bed can affect the gallium separation rate. The testing defined by Tables 3.2.2-1 and 3.2.2-2 will be conducted with a fixed particle bed.

\begin{tabular}{|c|c|c|c|c|c|c|}
\hline \multirow[t]{2}{*}{ Temperature } & \multicolumn{3}{|c|}{$\begin{array}{c}\text { Gas flow Velocity } \\
1.5 \mathrm{~cm} / \mathrm{s}\end{array}$} & \multicolumn{3}{|c|}{$\begin{array}{l}\text { Gas flow Velocity } \\
3 \mathrm{~cm} / \mathrm{s}\end{array}$} \\
\hline & $\begin{array}{l}0.3 \\
\text { grams }\end{array}$ & $\begin{array}{l}0.9 \\
\text { grams } \\
\end{array}$ & $\begin{array}{l}2.5 \\
\text { grams }\end{array}$ & $\begin{array}{l}0.3 \\
\text { grams }\end{array}$ & $\begin{array}{l}0.9 \\
\text { grams }\end{array}$ & $\begin{array}{l}2.5 \\
\text { grams }\end{array}$ \\
\hline $600^{\circ} \mathrm{C}$ & $\sqrt{ }$ & $\bar{\checkmark}$ & $\sqrt{ }$ & $\bar{\checkmark}$ & $\bar{J}$ & $\bar{\checkmark}$ \\
\hline $800^{\circ} \mathrm{C}$ & $\sqrt{ }$ & $\sqrt{ }$ & $\sqrt{ }$ & & & \\
\hline $900^{\circ} \mathrm{C}$ & $\sqrt{ }$ & $\sqrt{ }$ & $\sqrt{ }$ & $\checkmark$ & $\checkmark$ & 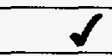 \\
\hline $1000^{\circ} \mathrm{C}$ & $\sqrt{ }$ & $\checkmark$ & $\sqrt{ }$ & & & \\
\hline $1100^{\circ} \mathrm{C}$ & $\sqrt{ }$ & $\sqrt{ }$ & $\sqrt{ }$ & & & \\
\hline $1200^{\circ} \mathrm{C}$ & $\checkmark$ & $\checkmark$ & $\sqrt{ }$ & $\bar{\checkmark}$ & $\sqrt{ }$ & $\checkmark$ \\
\hline
\end{tabular}

Table 3.2.2-1. $\mathrm{PuO}_{2}$ gallium evolution test matrix for $0.5-\mathrm{hr}$ tests

\begin{tabular}{|l|r|r|l|}
\hline \multirow{2}{*}{ Temperature } & \multicolumn{3}{|c|}{ Gas flow Velocity } \\
& 0.3 & 0.9 & $\mathrm{~cm} / \mathrm{s}$ \\
& $\begin{array}{l}0.3 \\
\text { grams }\end{array}$ & $\begin{array}{l}2.5 \\
\text { grams }\end{array}$ & grams \\
\hline $600^{\circ} \mathrm{C}$ & $\checkmark$ & $\checkmark$ & $\checkmark$ \\
\hline $900^{\circ} \mathrm{C}$ & $\checkmark$ & $\checkmark$ & $\checkmark$ \\
\hline $1200^{\circ} \mathrm{C}$ & $\checkmark$ & $\checkmark$ & $\checkmark$ \\
\hline
\end{tabular}

Table 3.2.2-2. $\mathrm{PuO} 2$ gallium evolution test matrix for 4-hr tests

Characterization will include gallium concentration and the particle morphology (i.e. size distribution and surface area).

\subsection{Surrogate $\left(\mathrm{CeO}_{2}\right)$ Validation}

The $\mathrm{CeO}_{2}$ will be validated for acceptance as a $\mathrm{PuO}_{2}$ surrogate by duplicating selected $\mathrm{PuO}_{2}$ gallium evolution process optimization testing. This approach will allow leveraging of the $\mathrm{PuO}_{2}$ process optimization data for surrogate validation. The $\mathrm{PuO}_{2}$ process optimization test conditions are defined in Table 3.2.2-1 and Table 3.2.2-2. Not all of the conditions selected for $\mathrm{PuO}_{2}$ process optimization testing will necessarily be duplicated for the $\mathrm{CeO}_{2}$ validation testing. A balanced selection of the most significant test conditions will be chosen for duplication.

In the event that the surrogate can not be validated (i.e. the behavior of $\mathrm{CeO}_{2}$ and $\mathrm{PuO}_{2}$ do not correspond), the program will proceed with the prototypic testing, although at an increased level of risk. In particular, cold prototypic testing will be compromised 
somewhat if a valid surrogate does not exist. Any required engineering changes following the initial processing checkout would be difficult incorporate on a hot (contaminated) system. It may be possible to find an alternate cold surrogate which does not duplicate plutonium-gallium evolution behavior, but duplicates $\mathrm{PuO}_{2}$ particle dynamics.

\subsection{PROTOTYPE DESIGN AND TESTING}

The prototypic design effort will be focused on two primary activities. First, a system design will be selected which can provide the process conditions selected from the process development test results. As much as possible, this system design will consist of off-theshelf equipment. Second, materials will be selected which allow operating the selected system at the design conditions. In particular, this relates to the concern over gallium reactivity with system components, and any moving parts at elevated temperatures.

The prototypic testing will consist of (1) cold checkout phase, (2) hot checkout phase, and a (3) prototypic demonstration. These tests will be conducted during FY99, and the test planning will be initiated later in FY98.

\subsection{Prototype Design}

As a starting point for the prototype design, consideration will be given to off-the-shelf equipment. One example of off-the-shelf equipment which is used for processing similar to that which will be needed for the TIGRS is a calciner. For instance, Los Alamos has used both fixed-bed batch-type kiln/calciners and inclined-rotary continuous-type kiln/calciners for production of $\mathrm{PuO}_{2}$ from oxalate precipitate. While the fixed-bed can be operated at higher temperatures than the inclined-rotary, and the inclined-rotary achieves greater gas/solid mixing than the fixed-bed, it is likely that neither have been used for $\mathrm{PuO}_{2}$ at temperatures high enough for gallium removal.

\subsubsection{Mechanical}

Perhaps one of the most important aspects of the mechanical design will be whether a fixed-bed batch-type processing device will suffice. If it is determined that a fixed-bed device can not provide adequate gas/particle mixing, then the design will become more complicated along the line of a inclined-rotary continuous-type device. This will add complexity to the design with regard to including more moving parts at elevated operating temperatures. While similar equipment has been used for years in the mining industry at processing temperatures far in excess of what will be required for gallium separation, the application for plutonium processing creates numerous unique challenges. For instance, locating an off-the-shelf design for TIGRS operating temperatures while matching the processing rate and satisfying the criticality requirements will probably be very difficult. For these reasons, the mechanical design effort will require a significant level of creativity if existing technology is used. 


\subsubsection{Materials}

Two primary questions exist with regard to materials. First, what fabrication materials must be changed if the off-the-shelf equipment is operated at significantly higher than original design conditions? Second, what will be the effect of highly reactive gallium on the system materials? Should a gallium getter be included in the design, and if so what should the getter material consist of, and should it be internal or external to the processing chamber?

\subsection{Prototype Testing}

This is a FY99 activity.

\subsection{MAJOR MILESTONES/DELIVERABLES}

$\mathrm{PuO}_{2}$ received for process development Systems requirement document ${ }^{*}$

Hot R\&D testing*

Cold prototypic testing*

Hot prototypic testing

Prototypic demonstration test ${ }^{*}$
Initiate ongoing ongoing ongoing $11 / 01 / 98$ $04 / 01 / 99$

07/01/99
Complete

$01 / 01 / 98$

$04 / 01 / 98$

$07 / 01 / 98$

$04 / 01 / 99$

$05 / 28 / 99$

09/30/99

${ }^{*}$ Report due 